\title{
Tratamiento fotográfico en webs periodísticas de la Universidad de Porto. Análisis descriptivo basado en indicadores de calidad
}

\author{
Joaquín LÓPEZ DEL RAMO \\ Universidad Rey Juan Carlos. Facultad de Ciencias de la Comunicación. \\ Departamento de Ciencias de la Comunicación y Sociología \\ joaquin.lopezdelramo@urjc.es
}

Recibido: Septiembre 2015

Aceptado: Noviembre 2015

\begin{abstract}
Resumen: Este trabajo da cuenta de una investigación realizada en 2014 que aborda la descripción y caracterización del tratamiento general de la fotografía en tres portales periodísticos con altos estándares de calidad auspiciados por la Universidade do Porto (P3, JPN y Ciência 2.0). Sobre la opción metodológica del análisis de contenido, y utilizando como herramienta para la obtención de datos un libro de códigos multidimensional de diseño propio, se concluye que existen fortalezas y carencias comunes entre los tres medios objeto de estudio, las cuales no difieren en exceso de las detectadas por otros estudios sobre medios profesionales de prensa digital. Las principales fortalezas con un alto grado de empleo de contenidos fotográficos, correcta maquetación y coherencia en la interactividad. Junto al abuso de las fotografías muy pequeñas, el principal problema detectado es que las fotografías poseen un valor informativo muy escaso, limitado en la mayoría de los casos a una función decorativa.
\end{abstract}

Palabras clave: Análisis de contenido; Ciberperiodismo; Fotografía; Interactividad; Maquetación; Prensa universitaria; Universidade do Porto.

\section{Photographic treatment in newspaper sites from Porto University. Descriptive analysis based on quality indicators}

\begin{abstract}
This work gives an account of his investigation in 2014 that deals with the description and characterization of the general treatment of the photograph in three newspaper portals sponsored by the Universidade do Porto with high standards of quality (P3, JPN and Ciência 2.0). On the methodological choice of content analysis, using as a tool for data collection a book of multidimensional codes own comes to the conclusion that there are strengths and gaps between the three common means object of study, which do not differ in excess of those detected by other studies to professional media digital press. The main strengths with a high degree of use of photographic content, layout and correct consistency interactivity. Next to the abuse of very small photographs, the main problem identified is that the pictures have very little information value, limited in most cases to a decorative function.
\end{abstract}

Keywords: Cyberjournalism; Content Analysis; Desktop Publishing; Interactivity; Photography; Universidade do Porto; University Press. 


\section{INTRODUCCIÓN}

El diseño de la prensa digital ha experimentado durante los últimos años un cambio de tendencia que otorga mayor preponderancia al componente visual respecto al textual. Las imágenes, y especialmente las fotografías, ganan tamaño y protagonismo de forma acelerada, en detrimento del espacio dedicado a los textos, lo cual es especialmente palpable en las páginas principales. En cierta forma, se trata de un proceso que ya tuvo lugar históricamente en las publicaciones informativas impresas, pero en este caso producido de una manera mucho más rápida, intensa y acentuada.

Este fenómeno comenzó a vislumbrarse desde la segunda mitad de la década 2000, y al mismo se refirió el artículo "Newspapers: Not Visual Enough for the Future?” (Van Dusseldorp, 2007), publicado en Pointer.org, en el que recogían algunas ideas de John Naisbitt sobre la evolución futura de la prensa que hoy están plenamente vigentes:

Los periódicos y las revistas tienen que reinventarse a sí mismos, ya que la gente está leyendo menos, especialmente a los jóvenes. Mientras, por otro lado, recibimos imágenes constantemente (...) nuestra cultura es cada vez más visual.

El papel de las palabras está declinando, mientras que el de los recursos visuales está subiendo (...) los periódicos no son lo suficientemente visuales para los estándares de la cultura de hoy en día (....) tendrán que adaptarse a la cultura visual en la que estamos, lo que incluye en gran medida más colores, infografías, fotos, dibujos animados y otros elementos.

La enfatización de los contenidos visuales tiene por objeto la creación un producto periodístico de mayor atractivo e impacto. La imagen fotográfica es el elemento sobresaliente en este contexto, debido a su isomorfismo con el objeto real que representa y a estar dotada de una poderosa carga cognitivo-afectiva, en su capacidad de "expresar fácilmente emociones en un lenguaje que todos hablan" (Bruder, 2007: 1). El empleo de ilustraciones generosas y la mejora de los niveles de claridad visual son algunas de las principales tendencias de futuro para la industria de prensa señaladas también por el diseñador alemán Norbert Küpper (Küpper, 2015: 3-4) en la última edición del European Newspaper Award, certamen anual que premia los mejores trabajos e iniciativas profesionales realizadas en este campo dentro de nuestro continente.

Las conclusiones del reciente estudio de Engaging News Project "Homepage Layout” (Stroud; Curry; Cardona; Peacock, 2015), desarrollado por el Instituto Strauss Annette, de la Universidad de Austin-Texas, avalan empíricamente la 
preferencia del público hacia las páginas principales de web periodísticas basadas en imágenes respecto a aquellas de diseño clásico, más textuales. Los datos son concluyentes, puesto que las páginas de diseño “contemporáneo” (más visuales) superan nítidamente a las "clásicas" (más textuales) en todos los parámetros contemplados en esta investigación: cantidad de visitas, estímulo de la lectura, retención de datos y experiencia general de usuario. Además, estas diferencias de valoración son independientes de la edad, la educación, o nivel de conocimiento de los encuestados, lo que aun refuerza más sus resultados.

En consonancia con lo anteriormente indicado, las últimas estrategias de rediseño implantadas por importantes medios informativos digitales de carácter internacional presentan una orientación casi totalmente coincidente: primar la visualidad, haciendo de la fotografía el tipo de contenido dominante. En dicho sentido, pueden tomarse como ejemplos significativos los rediseños de USA Today (www.usatoday.com/), The Guardian (www.theguardian.com/international), Los Angeles Times (www.latimes.com/), Chicago Tribune (www.chicagotribune. com/), El Nuevo Herald (www.elnuevoherald.com/) o Stern (www.stern.de/), que siguen un estilo semejante a los de NBC News (www.nbcnews.com/) o Bloomberg View (www.bloombergview.com/), entre otros.

La ganancia de protagonismo de lo visual en los medios ciberperiodísticos, con la fotografía como estandarte, se ha descrito y justificado suficientemente por los trabajos citados y otros publicados sobre la misma cuestión en fechas recientes (Sánchez Vigil, 2014). Se presupone que esta “explosión” de la imagen no es sólo cuantitativa, sino que necesariamente también debería tener efectos cualitativos, especialmente en cuanto a un enriquecimiento efectivo del mensaje. Este último aspecto, que desvela el auténtico valor informativo de las imágenes fotográficas, requiere para su examen procesos analíticos más profundos. Cabría cuestionarse si en el nuevo escenario de visualidad a ultranza, persisten las disfunciones en el tratamiento fotoperiodístico online detectadas con anterioridad por diversas investigaciones, desaparecen o surgen otras nuevas, aunque ello exceda los objetivos del presente trabajo.

Las investigaciones realizadas hasta el momento sobre el tratamiento de la fotografía en periódicos digitales están referidas por lo general a versiones de diarios anteriores a los rediseños visuales mencionados. Centrándonos en nuestro entorno geográfico más cercano, los análisis de Caminos, Marín, y Armentia (2008), López del Ramo (2010), Sánchez Vigil, Marcos Recio y Olivera Zaldua (2011 y 2014) y Masip, Micó y Meso (2012) coinciden en constatar una serie de insuficiencias que se observan de manera reiterada y menoscaban la aportación de la fotografía al mensaje informativo en la prensa digital, como son:

- Reducido tamaño y baja calidad

- Uso masificado, especialmente en las páginas principales de los periódicos

- Tratamiento caótico, confuso y poco coherente 
- Abuso del encuadre corto

- Abuso de los retratos

- Escasa aportación noticiosa, por limitarse a una función complementaria o simplemente decorativa para llamar la atención

Como en cualquier esfera periodística, los grandes medios informativos de Internet marcan la evolución de las tendencias. Aquellos que cuentan con mayor prestigio y difusión a escala internacional sirven como referencia a los de vocación más nacional, local o centrados en grupos o contextos más restringidos. La rapidez y flexibilidad consustanciales al entorno web permiten implementar estos procesos de cambio, que podríamos calificar como "imitativos" o "a la moda", con una rapidez vertiginosa.

La incorporación en las Facultades de Ciencias de la Comunicación de disciplinas y tecnologías relacionadas con el ciberperiodismo ha dado lugar al surgimiento en este ámbito académico de sitios web noticiosos que, en algunos casos, se aproximan a un nivel profesional. Aun no siendo comparables los enfoques, públicos y medios materiales y humanos con los medios de comunicación profesionales, sí es cierto que una parte las publicaciones digitales universitarias más avanzadas adoptan métodos y estándares de trabajo profesionales y, en muchos casos, así como el estilo de diseño y visualidad actualmente imperante en sus "hermanos mayores". Por tanto, puede resultar interesante tratarlos como objeto de estudio "per se" como, e incluso analizar sus diferencias y similitudes con los sitios web que concurren en el gran mercado mediático.

La sección de Ciências da Comunicaçao dependiente de la Facultade de Letras de la Universidad portuguesa de Porto (en adelante CC-FLUP) es un paradigma en ese sentido, al contar tres publicaciones periodísticas digitales independientes entre sí, de diferente alcance, objetivos y estructura, pero organizadas con criterios profesionales o muy cercanos al paradigma de una sala de redacción real. No son sólo una plataforma de prácticas para los alumnos (aunque algunos de ellos también cumplan ese papel), sino que, cada uno con su propia estrategia, generan un producto informativo de calidad, con contenidos variados y ciclos de actualización rápida. Dichos portales son fruto de varias iniciativas y proyectos, que se describen seguidamente en sus líneas fundamentales:

P3 (http://p3.publico.pt/) es una plataforma online de noticias e información nacida de un acuerdo de colaboración entre la Universidad y la empresa editora del diario portugués "Público", el más importante del país vecino en el ámbito online. Su equipo de redacción está conformado como un staff estable. Desde el punto de vista estructural y operativo, es un sub-portal vinculado a la web del propio diario Público.pt, en el cual tiene su dominio. 
- Orientación: producto profesional realizado en un entorno de trabajo real

- Tipo de público al que se orienta: preferentemente joven de 18 a 35 años

- Temática esencial: socio-cultural (música, cine, exposiciones, libros, diseño, fotografía, arquitectura y deporte)

- Secciones: Cultura, Actualidad, Vicios (término portugués) (visibles en barra de navegación principal). Râguebi, Galería y Gallery (sumergidas)

- Equipo: mixto, entre profesionales de Público.pt y postgraduados (ex alumnos del Centro) que han superado pruebas curriculares y selectivas

- Política sobre contenidos visuales o multimedia: sinergia entre diferentes media, estrategia multimedios, abierta a la inclusión de colaboraciones del público. Apuesta creciente por el contenido multimedia

JPN (Jornalismo Porto Net) (http://jpn.up.pt/) es una plataforma de noticias de información general gestionado por la sección de Ciências da Comunicaçao de la FLUP. Centra su interés la ciudad de Porto y en la propia Universidad, aunque puede recoger informaciones de otra escala geográfica.

- Orientación: semi-profesional. Tiene como objetivo básico profundizar en las competencias teórico-prácticas de los alumnos que aún cursan los estudios de Periodismo mediante la creación de una publicación real en abierto

- Tipo de público al que se orienta: general

- Temática: generalista

- Secciones: UP, Porto, País, Mundo, Economía, Cultura, Educación, Ciencia y Tecnología, Desporto, Media

- Equipo: los directores son profesores del Centro, los editores son exalumnos postgraduados con amplia experiencia y el resto de equipo alumnos que aún cursan sus estudios de Periodismo

- Política sobre contenidos visuales o multimedia: poner en práctica las más modernas técnicas de expresión en Internet

Ciência 2.0 (www.ciencia20.up.pt/) es un portal surgido de un proyecto de comunicación y divulgación científica co-financiado por el Fondo Europeo de Desarrollo (FEDER), a través del Quadro de Referência Estratégico Nacional (QREN) y del Programa Operacional Fatores de Competitividade (COMPETE), además de fondos del programa Ciência Viva. Su dirección la ostenta un profesor de la Universidad y su equipo de redacción posee un carácter estable.

- Orientación: profesional. Su objetivo básico es comunicar la ciencia en todas sus variantes y manifestaciones

- Tipo de público al que se orienta: general

- Temática: Ciencia y tecnología 
- Secciones: La estructura del portal mezcla contenidos informativos con otro tipo de servicios. Las secciones informativas son: Astronomía, Biología, Ciencia y Arte, Ciencia forense, Física, Geología, Historia, Matemática, Piscología, Química, Saude y Tecnología

- Equipo: La dirección la ostenta un profesor de la FLUP y los redactores son ex alumnos postgraduados

- Política sobre contenidos visuales o multimedia: sinergia entre diferentes media, estrategia multimedios, abierta a la inclusión de colaboraciones del público

La solvencia de estos tres proyectos, su diversidad de enfoques y su fuerte anclaje institucional en la CC-FLUP supone un caso excepcional dentro del ámbito universitario ibérico, y por ello, también teniendo en cuenta su posible valor representativo, se ha considerado de interés como objeto de estudio en relación al tratamiento general de la fotografía.

\section{OBJETIVOS}

El presente trabajo se plantea como objetivo general realizar el estudio descriptivo del tratamiento de la fotografía en los portales P3, Ciência 2.0 y JPN, a fin de caracterizar sus debilidades y fortalezas desde una visión centrada en la perspectiva de usuario, y en relación a la tendencia de primacía de la visualidad vigente en el diseño web. Se obvia el análisis de las galerías fotográficas y otros productos multimedia característicos de los periódicos digitales, al poseer éstos especificidades que les confieren una autonomía estructural y significativa propia, por lo que su examen sistemático requeriría por su extensión un trabajo monográfico.

Los objetivos específicos son:

1. Determinar el nivel de claridad, facilidad de uso, intuitividad y coherencia en el tratamiento general de la fotografía en los tres sitios web objeto de estudio.

2. Aplicar un procedimiento de análisis que incluye aspectos relativos al contexto de página y la interactividad, a menudo escasamente tenidos en cuenta en estudios sobre la fotografía.

3. Complementar investigaciones anteriores centradas en grandes periódicos, a fin de aportar datos sobre el tratamiento fotoperiodístico en medios noticiosos de ámbito universitario, que pueden considerase a priori como preprofesionales.

4. Comprobar si los portales informativos universitarios presentan las mismas carencias básicas en el tratamiento de la fotografía observadas en los periódicos online pertenecientes al mercado profesional. 
5. Colaborar en la mejora de los estándares de calidad en el tratamiento de la fotografía por parte de estos medios, dentro de un enfoque más centrado en el usuario, basándose en datos objetivos proporcionados por una fuente externa.

\section{METODOLOGÍA}

Este trabajo recoge parte de los resultados de una estancia de investigación desarrollada por su autor en las instalaciones del Polo de Ciências da Comunicação de la Facultade de Letras Universidade de Porto, durante el mes de junio de 2014. El factor motivador de la misma fue el reconocido prestigio con que cuenta este centro en el campo del periodismo digital, materializado de forma tangible en el desarrollo de los proyectos P3, JPN y Ciência 2.0.

\subsection{DETERMINACIÓN DE LA MUESTRA}

Para la elección de la muestra, se partió como la premisa de la unidad visualestructural que normalmente caracteriza a los sitios web periodísticos. Esto implica que las páginas de un mismo nivel jerárquico pertenecientes al sitio (secciones, apartados, subapartados, etc.) poseen una retícula similar, o con ligeras variantes, y la maquetación de los elementos de superficie (en este caso las fotografías) es idéntica o muy semejante. La unidad visual-estructural fue confirmada mediante la exploración exhaustiva de los tres portales objeto de análisis. Al ser semejantes las páginas del mismo nivel, se hizo innecesario someter a análisis la totalidad de mismas, con la consiguiente economía de tiempo, a la vez que se evitaba la redundancia de los datos. Por ello, se tomó como unidad de análisis una página representativa de cada nivel estructural del sitio, considerando los niveles existentes por igual en los tres portales considerados (P3, JPN y Ciência 2.0):

- Home (primer nivel)

- Secciones (segundo nivel)

- Apartados (tercer nivel)

La ficha de codificación que se describe más adelante fue aplicada a cada una de las unidades de análisis, es decir a una página por nivel jerárquico de cada portal. Al existir un cuarto nivel de profundidad únicamente en P3, y no en JPN ni Ciência 2.0, no fue considerado. El navegador empleado fue Google Chrome, en un equipo dotado de sistema operativo Windows 8.0. 


\subsection{PROCEDIMIENTO}

En función de los objetivos anteriormente descritos, se consideró que el procedimiento metodológico idóneo para este trabajo era el análisis de contenido, ya que, como indica Igartua (2006:181):

(...) el análisis de contenido se puede utilizar para diseccionar cualquier producto de comunicación mediática, para conocerlo por dentro, para saber cómo está hecho, para inferir y predecir su mecanismo de influencia. Esta técnica de investigación cuantitativa que presenta las ventajas de ser sistemática, objetiva y minuciosa; tiene una orientación empírica, pues se basa en la observación de la realidad con apoyo en datos reales.

Se examinan las características de las fotografías desde el punto de vista del receptor externo, tal como aparecen publicadas en los medios, obviando los posibles condicionantes internos (tecnológicos, productivos o de otra naturaleza) que el público ignora en la mayor parte de los casos. Interesan las características visualizadas en las páginas web, más allá de las motivaciones que las expliquen.

\subsection{INSTRUMENTO}

La herramienta empleada en el proceso de codificación ha sido una ficha de diseño original basada en el "Modelo de análisis de contenido de la fotografía periodística desde el plano documental e informativo" (López del Ramo, 2014). El diseño de esta ficha integra las aportaciones de trabajos teóricos españoles clásicos de referencia sobre el análisis de la fotografía en prensa escrita, como los de Vilches (1987), Rodríguez Merchán (1993), Alonso Erausquin (1995), Sousa (2004) y Marzal (2004), y además tiene en cuenta los estándares de usabilidad web relacionados con la fotografía o aplicables a ella definidos por Nielsen (2006), Hassan y Martín (2003), Horton (2006) y Krug (2006).

Buena parte de las investigaciones sobre fotografía en medios digitales han sido una traslación de las de los medios impresos, pues básicamente se han centrado en examinar el contenido intrínseco de las imágenes, es decir, los elementos del marco interior: lo representado en ella, el mensaje que transmite y su carga documental. También, se ha evaluado por parte de diferentes estudios la relación semántica de la imagen con los elementos textuales circundantes, como titulares y pies de foto (Marsh y White, 2003). Pero en los periódicos digitales, un examen integral de la fotografía obliga a tener en cuenta, además del contexto gráfico (la página donde se publica), otro más amplio, cual es el entramado hipertextual o hipermedial de la web, del que la fotografía puede formar parte como unidad de información o nodo conectado con otros. 
Los medios digitales añaden a la fotografía un atributo del que carece el soporte impreso impresos: la interactividad. Esto implica que las imágenes, además de visibles, también son usables, es decir, tienen funcionalidad. Por ello, es preciso asumir los preceptos relacionados con uno de los requerimientos básicos en el entorno online: la usabilidad, factor definido por la ISO 9241-11 (1998) como el grado de eficacia, eficiencia y satisfacción con la que usuarios específicos pueden lograr objetivos específicos en contextos de uso específicos. Se exige que cualquier producto web sea claro, fácil de comprender, intuitivo y predecible. La usabilidad de la fotografía depende de dos aspectos fundamentales: su grado de visibilidad y su funcionalidad como elemento interactivo, es decir, perteneciente a alguna de las tramas estructurales anteriormente mencionadas.

Por tanto, el concepto de calidad aplicado al tratamiento fotográfico en los diarios digitales estaría necesariamente vinculado, al menos, con dos dimensiones fundamentales:

- Grado de aportación informativa y expresiva al mensaje noticioso.

- Facilidad de uso, claridad comunicativa y coherencia.

Con arreglo a estas premisas, la ficha de codificación está compuesta por un conjunto de 25 variables o indicadores agrupados en tres categorías lógicas, según el tipo de contenido al que se refieren. Debe tenerse en cuenta que la pretensión no ha sido realizar un registro sistemático de todas las características fotográficas posibles y sus correlaciones contextuales, sino centrarse en aquellas especialmente relevantes en relación a los objetivos del trabajo y, de manera fundamental, en las que son más fácil y rápidamente perceptibles por del lector en Internet.

A continuación se realiza una descripción explicativa de esta ficha, indicando los posibles valores de cada variable y, en caso de poseer éstos un sesgo cualitativo, se señala cuál es el valor idóneo según los criterios de buenas prácticas ampliamente reconocidos por la comunidad científica y profesional del fotoperiodismo y el diseño web, a su vez recogidos en las obras referenciadas con anterioridad.

Factores de contexto de página: características de maquetación que afectan a la visibilidad y énfasis de la fotografía, fruto de las diferentes interrelaciones visuales que se producen en la página. Están vinculadas con dos aspectos básicos del diseño periodístico: la jerarquización, y la claridad.

Indicador 1.1: Tipo de contenido predominante en la página por espacio ocupado. Valores posibles: Imagen. Texto. Equilibrio. Otros

Indicador 1.2: Número de fotografías por página. No se computan fotografías de encabezados, epígrafes, menús, carruseles dinámicos, etc., sino únicamente aquellas que ilustran los contenidos informativos de la página. 
Indicador 1.3: Numero de tamaños diferentes de las fotografías publicadas en la misma página.

Indicador 1.4: ¿Se compone con una foto a mayor tamaño que el resto?

Valor idóneo: Sí. Favorece la jerarquización

Indicador 1.5: ¿Se observa el efecto "cromos” o "miniaturas”?

Descripción: Imágenes de tamaño muy reducido en las cuales es difícil o imposible apreciar detalles.

Valor idóneo: No. Las fotos excesivamente pequeñas no permiten apreciar detalles y se perciben como ruido.

Indicador 1.10: ¿ ¿Se mezclan en el mismo panel o área de retícula fotografías con otros contenidos visuales (imágenes o vídeos) sin distinción o separación clara?

Valor idóneo: No. La separación de contenidos de diferente naturaleza favorece la claridad y la jerarquización.

Indicador 1.11: ¿ ¿Se mezclan en el mismo panel o área de retícula fotos con publicidad sin separación clara?

Valor idóneo: No. La separación visual de contenidos de naturaleza comercial e informativa favorece la claridad y es una praxis más ética.

Indicador 1.12: ¿Todas las fotos relacionadas con un bloque textual se asocian claramente al mismo?

Valor idóneo: Sí. Lo contrario puede producir confusión,

Indicador 1.13: Presencia de pie de foto.

Indicador 1.14: Existencia de fotos con texto sobrescrito.

Descripción: Presencia de texto escrito en el marco interior de la fotografía,

Indicador 1.15: Identificación de la autoría.

Valor idóneo: Sí, por ser indicativo de transparencia.

2.Rasgos intrínsecos de la fotografía: particularidades formales apreciables dentro del marco de la imagen. En este caso sólo se toman en consideración las características más clara y rápidamente perceptibles para el lector, sin ánimo de analizar los atributos documentales, el contenido y el mensaje connotativo profundo de la fotografía.

Indicador 2.1: Valor noticioso.

Valores posibles: Informativo: la imagen ofrece datos relevantes.

Ilustrativo-decorativo: la imagen aporta datos anecdóticos o prescindibles.

Valor idóneo: Informativo, ya que la foto aporta mensaje.

Indicador 2.2: Encuadre predominante.

Descripción: porción del campo visual captado en la imagen.

Valores posibles: Corto-medio. General

Indicador 2.3: Empleo de fotografías de posado o retrato.

Descripción: fotografías protagonizadas por personajes humanos que se sitúan preconcebidamente con vistas a la cámara. 
Valor idóneo: su empleo abusivo no se considera positivo, por dar una imagen estereotipada.

Indicador 2.4: Empleo de fotografías genéricas o de avatar.

Descripción: fotografías no relacionadas directamente con los contenidos informativos o pertenecientes a autores o redactores de alguna de las noticias publicadas en la página.

Valor idóneo: Neutro, pero su aportación al mensaje informativo es nula y su empleo excesivo se considera inadecuado.

Indicador 2.5: Utilización de fotomontajes.

Valor idóneo: No, dado que la mezcla de imágenes puede generar confusión, especialmente en fotomontajes de tamaño reducido.

3. Características de interactividad: Informan sobre aspectos de funcionalidad referidos a la navegación y a la orientación del usuario en las fotografías que poseen vínculo.

Indicador 3.1: Promedio de fotografías con vínculo.

Valor ideal: seguir una pauta común en todas las páginas del sitio web, a fin de no desorientar al usuario.

Indicador 3.2: ¿Se indica en algún caso y sin actuación del usuario que las fotos llevan vínculo?

Valor idóneo: Sí. El usuario sabe de antemano que la foto tiene vínculo sin obligarle a realizar ninguna interactuación para adivinarlo.

Indicador 3.3: ¿Las fotos con vínculo llevan asociado un efecto visual dinámico en estado on-mouse?

Descripción: cuando se desliza el ratón sobre la foto, ésta cambia de aspecto (video inverso, borde resaltado, etc.)

Valor idóneo: Sí, porque orientan al usuario. Es conveniente un tratamiento semejante de este aspecto en todas las páginas del sitio.

Indicador 3.4: Tipo de destino del vínculo.

Valores posibles: Interno (dentro del mismo sitio web). Externo (documento de otro sitio web).

Indicador 3.5: ¿ ¿isualización en destino de la misma fotografía?

Descripción: Si al pulsar el enlace sobre la fotografía, la página o documento donde se llega muestra esa misma fotografía.

Valores: Siempre. Variable, Nunca

Valor idóneo: Siempre. Refuerza la coherencia visual y la orientación del lector

\section{RESULTADOS}

Se presentan a continuación los resultados obtenidos y una lectura básica de los mismos en dos escalas: 
- Resultados por niveles jerárquicos individuales

- Contraste de resultados entre niveles jerárquicos

\subsection{RESULTADOS POR NIVELES JERÁRQUICOS}

\subsubsection{PÁGINA PRINCIPAL}

Dentro de la estructura jerárquica de las webs, la página principal ocupa el primer nivel de la jerarquía y es la que está asociada automáticamente con la URL del dominio. Su temática es general, a modo de "escaparate”. En este caso se han analizado las siguientes:

- P3: http://p3.publico.pt/. Primera consulta: 13 junio 2014, 11'00 horas.

- JPN: http://jpn.c2com.up.pt/ (actualizada a http://jpn.up.pt/)

Primera consulta: 16 junio 2014, 17'00 horas

- Ciência 2.0: www.ciencia20.up.pt/. Primera consulta: 12 junio 2014, 16'00 horas

Tabla 1. Factores de contexto de página relacionados con la fotografía en páginas principales

\begin{tabular}{|l|c|c|c|}
\hline \multicolumn{4}{|c|}{ Factores de contexto de página } \\
\hline Indicadores & P3 & JPN & Ciência 2.0 \\
\hline Contenido predominante & Imagen & Texto & Imagen \\
\hline Número de fotos & 8 & 10 & 5 \\
\hline Número de tamaños & 4 & 3 & 2 \\
\hline $\begin{array}{l}\text { Se compone con una } \\
\text { fotografía de tamaño mayor }\end{array}$ & Sí & Sí & Sí \\
\hline Efecto "miniatura" & $37,5 \%$ & $90 \%$ & No \\
\hline $\begin{array}{l}\text { Mezcla de fotografías con } \\
\text { otros contenidos visuales }\end{array}$ & Sí & No & Sí \\
\hline $\begin{array}{l}\text { Mezcla de fotografías con } \\
\text { inserciones publicitarias }\end{array}$ & Sí & No & No \\
\hline $\begin{array}{l}\text { Todas las fotos se asocian } \\
\text { claramente con los textos } \\
\text { relacionados }\end{array}$ & Sí & Sí & Sí \\
\hline Pies de foto & & & No \\
\hline Texto sobrescrito & Sí & Sí & No \\
\hline Identifica autoría & No & No & No \\
\hline
\end{tabular}

Los resultados fundamentales expuestos en la Tabla 1 revelan un predominio del contenido visual en dos de los tres portales, con un número de fotos que varía entre un máximo de 10 y un mínimo de 5 . En cuanto a su maquetación, en todos los casos se emplean fotos de diferentes tamaños, oscilando entre un máximo de 4 y un mínimo de 2. La utilización de fotografías de tipo "miniatura" se aprecia en 2 de las 3 páginas, siendo muy acusado en una de ellas. Las fotografías se combinan con otros elementos visuales en la misma zona de la página en 2 de las 3 páginas principales, mientras que la mezcla con publicidad se constata sólo en 1 de las 3 
páginas. La asociación de las fotos con los textos que las acompañan es óptima en todos los casos. No se emplean pies de foto, pero, sin embargo, el texto sobrescrito es una práctica bastante generalizada. No se indica la autoría de la imagen.

Tabla 2. Rasgos intrínsecos a la fotografía en páginas principales

\begin{tabular}{|l|c|c|c|}
\hline \multicolumn{4}{|c|}{ Rasgos intrínsecos a la fotografía } \\
\hline Indicadores & P3 & JPN & Ciência 2.0 \\
\hline Valor noticioso & $\begin{array}{c}100 \% \text { decorativo- } \\
\text { ilustrativo }\end{array}$ & $\begin{array}{c}100 \% \text { decorativo- } \\
\text { ilustrativo }\end{array}$ & $\begin{array}{c}100 \% \text { decorativo- } \\
\text { ilustrativo }\end{array}$ \\
\hline Encuadre predominante & $\begin{array}{c}90 \% \text { corto-medio } \\
10 \% \text { general }\end{array}$ & $\begin{array}{c}70 \% \text { corto-medio } \\
30 \% \text { general }\end{array}$ & $\begin{array}{c}90 \% \text { corto-medio } \\
10 \% \text { general }\end{array}$ \\
\hline Uso de retrato o posado & Sí & Sí & No \\
\hline $\begin{array}{l}\text { Fotos genéricas o de avatar } \\
(\%)\end{array}$ & $10 \%$ & No & No \\
\hline Fotomontajes & Sí & No & No \\
\hline
\end{tabular}

Los datos expuestos en la Tabla 2 muestran que en todos los casos el valor noticioso de las imágenes es simplemente decorativo. Predominan en todas las páginas las fotografías de encuadre corto-medio, aunque se presentan combinadas con otras de plano general. Se hace uso de fotografías de posado o retratos en 2 de las 3 páginas. No se emplean fotos genéricas o de avatar en 2 de las 3 páginas, y la publicación de fotomontajes se limita a 1 de los tres casos analizados.

Tabla 3. Características interactivas en fotografías de páginas principales

\begin{tabular}{|l|c|c|c|}
\hline \multicolumn{3}{|c|}{ Características interactivas } \\
\hline Indicadores & IP3 & JPN & Ciência 2.0 \\
\hline Fotografías con vínculo & $62,5 \%$ & $100 \%$ & $100 \%$ \\
\hline $\begin{array}{l}\text { Se indica en algún caso que la foto lleva } \\
\text { vínculo }\end{array}$ & No & No & No \\
\hline Efectos on-mouse & Sí & No & Sí \\
\hline Tipo de destino & Interno & Interno & Interno \\
\hline $\begin{array}{l}\text { Visualización en destino de la misma } \\
\text { fotografía }\end{array}$ & Variable & Siempre & Variable \\
\hline
\end{tabular}

Respecto a las características de interactividad, se aprecia que en todas las páginas principales se publican fotografías que incluyen vínculos, y ello se da en un porcentaje elevado de imágenes. El lector no cuenta con indicativos estáticos que señalen o marquen la existencia de vínculos en las imágenes, salvo que sitúe el ratón sobre las imágenes con vínculo, cuando éstas presentan efectos visuales dinámicos (tipo roll-over) en 2 de los 3 casos. El 100\% de los vínculos en imágenes tienen como destino documentos internos, es decir, situados dentro del mismo sitio web, y en la mayor parte de los casos, cuando las fotografías llevan vínculos, el documento o elemento de destino muestra esa misma fotografía de forma destacada. 


\subsubsection{SECCIONES}

Las páginas equivalentes a lo que tradicionalmente se conoce en los periódicos como secciones ocupan el segundo nivel de la jerarquía de un sitio web. Su contenido alude a un ámbito temático determinado, pero complejo y susceptible de dividirse en subtemas o apartados. Como se indicó en un epígrafe anterior, la concordancia visual-estructural entre las páginas de los tres portales objeto de estudio ha permitido analizar una sola página por nivel secundario, al ser ésta representativa de sus homólogas.

- P3. Página de referencia: http://p3.publico.pt/cultura. Primera consulta: 13 junio 2014, 11'35 horas.

- JPN. Página de referencia: http://jpn.c2com.up.pt/porto/ (ya no disponible por cambio de la URL principal). Primera consulta: 16 junio 2014, 15,25 horas.

- Ciência 2.0. Página de referencia: www.ciencia20.up.pt/index.php?option= com_ciencia20categories\&view=generic\&themes[]=8\&Itemid=199. Primera consulta: 12 junio 2014, 17'00 horas.

Tabla 4. Factores de contexto de página relacionados con la fotografía en secciones

\begin{tabular}{|l|c|c|c|}
\hline \multicolumn{3}{|c|}{ Factores de contexto de página } \\
\hline Indicadores & P3 & JPN & Ciência 2.0 \\
\hline Contenido predominante & Imagen & $\begin{array}{l}\text { Imagen 50\% } \\
\text { Textual 50\% }\end{array}$ & Imagen \\
\hline Número de fotos & 4 & 9 & 8 \\
\hline Número de tamaños & 4 & 2 & 1 \\
\hline $\begin{array}{l}\text { Se compone con una fotografía de tamaño } \\
\text { mayor }\end{array}$ & Sí & No & No \\
\hline Efecto "miniatura" & $15 \%$ & $66,6 \%$ & No \\
\hline $\begin{array}{l}\text { Mezcla fotografías con otros elementos } \\
\text { visuales }\end{array}$ & Sí & Sí & No \\
\hline $\begin{array}{l}\text { Mezcla fotografías con inserciones } \\
\text { publicitarias }\end{array}$ & Sí & No & No \\
\hline $\begin{array}{l}\text { Todas las fotos se asocian claramente con } \\
\text { los textos relacionados }\end{array}$ & Sí & Sí & No \\
\hline Pies de foto & No & No & No \\
\hline Texto sobrescrito & Sí & No & No \\
\hline Identifica autoría & No & No & No \\
\hline
\end{tabular}

La lectura de los datos presentes en la Tabla 4 indica que la imagen es el contenido predominante en la mayoría de páginas de segundo nivel de los sitios analizados. El número de fotos oscila entre un máximo de 8 y un mínimo de 4 . En cuanto a su composición, el número de tamaños diferentes por página está comprendido entre un máximo de 4 y un mínimo de 1, mientras que la utilización de fotografías de tipo "miniatura" se observa en 2 de los 3 casos. Únicamente se compone con una foto con tamaño mayor del resto en 1 de las 3 páginas 
examinadas. Se entremezclan fotografías con otros elementos visuales si separación clara en 2 casos, y con inserciones publicitarias en 1 de las 3 páginas. Otro aspecto destacado es que la asociación de las fotografías con los textos a los que se refieren es nítida en la mayoría de las páginas. Tampoco en las fotos de las páginas pertenecientes a este nivel jerárquico se utilizan pies de foto, si bien en uno de los portales se recurre al empleo de texto sobrescrito en la imagen. En ningún caso se cita la autoría de las imágenes.

Tabla 5. Rasgos intrínsecos a la fotografía en secciones

\begin{tabular}{|l|c|c|c|}
\hline \multicolumn{4}{|c|}{ Rasgos intrínsecos a la fotografía } \\
\hline Indicadores & P3 & JPN & Ciência 2.0 \\
\hline Valor noticioso & $\begin{array}{c}100 \% \text { Decorativo- } \\
\text { ilustrativo }\end{array}$ & $\begin{array}{c}100 \% \text { Decorativo- } \\
\text { ilustrativo }\end{array}$ & $\begin{array}{c}100 \% \text { Decorativo- } \\
\text { ilustrativo }\end{array}$ \\
\hline Encuadre predominante & $\begin{array}{c}90 \% \text { corto-medio } \\
10 \% \text { general }\end{array}$ & $\begin{array}{c}66,6 \% \text { corto-medio } \\
33,4 \% \text { general }\end{array}$ & $\begin{array}{c}80 \% \text { corto-medio } \\
20 \% \text { general }\end{array}$ \\
\hline Retrato o posado & Sí & Sí & Sí \\
\hline $\begin{array}{l}\text { Fotos genéricas o de } \\
\text { avatar }\end{array}$ & $10 \%$ & No & No \\
\hline Fotomontaje & Sí & No & No \\
\hline
\end{tabular}

El análisis del tratamiento de las características intrínsecas a la fotografía en las secciones ofrece nuevamente como resultado que el valor noticioso se limita a una función ilustrativo-decorativa. Existe un claro predominio de los encuadres cortos, aunque éstos se combinan con fotos de plano general, y se utilizan fotografías de posado o retrato en todas las páginas. En empleo de fotos genéricas o de avatar únicamente se observa en una de las páginas, y en un porcentaje reducido, por lo que resulta minoritario. Se publican fotomontajes en 1 de los 3 casos evaluados.

Tabla 6. Características interactivas en fotografías en secciones

\begin{tabular}{|l|c|c|c|}
\hline \multicolumn{3}{|c|}{ Características interactivas } \\
\hline Indicadores & P3 & JPN & Ciência 2.0 \\
\hline Fotografías con vínculo & $100 \%$ & $100 \%$ & $100 \%$ \\
\hline $\begin{array}{l}\text { Se indica en algún caso que la foto } \\
\text { lleva vínculo }\end{array}$ & No & No & No \\
\hline Efectos on-mouse & Sí & No & No \\
\hline Tipo de destino & Interno & Interno & Interno \\
\hline $\begin{array}{l}\text { Visualización en destino de la misma } \\
\text { fotografía }\end{array}$ & Variable & Siempre & Siempre \\
\hline
\end{tabular}

Los datos recogidos en la Tabla 6 indican que todas las fotografías publicadas en las páginas de secciones incluyen vínculos. Como ocurre en las páginas principales, ninguna fotografía publicada en las de segundo nivel posee indicativos visuales que indiquen de la existencia de vínculos en las imágenes, y sólo cuando se sitúa el ratón sobre las imágenes con vínculo, éstas presentan efectos visuales dinámicos en 1 de los 3 casos. Desde el punto de vista funcional, los vínculos en 
imágenes dentro de este nivel jerárquico tienen como destino exclusivo documentos internos. En la mayor parte de las páginas de este nivel, cuando las fotografías llevan vínculos, en el documento o elemento de destino también se visualizan esas mismas imágenes.

\subsubsection{APARTADOS}

La arquitectura de contenidos habitual en los portales web informativos sitúa en el tercer nivel jerárquico a las páginas que, en la terminología clásica de la prensa, se suelen llamar apartados. Su contenido suele ser monotemático, pues tratan en extenso un único asunto. Por su coincidencia visual-estructural, también en este nivel también se ha procedido a analizar una sola página representativa de cada portal:

- P3. Página de referencia: http://p3.publico.pt/cultura/palcos. Primera consulta: 28 junio 2014, 19'00 horas.

- JPN. Página de referencia:

http://jpn.c2com.up.pt/2014/06/17/cultura_o_fado_vai_abarcar_em_vila_nova _de_gaia.html (ya no disponible por cambio de la URL principal). Primera consulta: 17 junio 2012, 16 '00 horas.

- Ciência 2.0. Página de referencia:

http://www.ciencia20.up.pt/index.php?option=com_content\&view=article\&id =544\&Itemid=199. Primera consulta: 12 junio 2014, 18'00 horas.

Tabla 7. Factores de contexto de página relacionados con la fotografía en apartados

\begin{tabular}{|c|c|c|c|}
\hline \multicolumn{4}{|c|}{ Factores de contexto de página } \\
\hline Indicadores & P3 & JPN & Ciência 2.0 \\
\hline Contenido predominante & Imagen & Textual & Textual \\
\hline Número de fotos & 11 & $1(*)$ & 1 a 3 \\
\hline Número de tamaños & 5 & No & 2 \\
\hline Se compone con una fotografía de tamaño mayor & Sí & - & Sí \\
\hline Miniaturas & $54,5 \%$ & No & No \\
\hline Mezcla fotografías con otros tipos de elementos visuales & No & No & No \\
\hline Se mezclan fotografías con inserciones publicitarias & No & No & No \\
\hline $\begin{array}{l}\text { Todas las fotos se asocian claramente con los textos } \\
\text { relacionados }\end{array}$ & Sí & Sí & Sí \\
\hline Pie de foto & No & Sí & No \\
\hline Texto sobrescrito & Sí & No & No \\
\hline Identifica autoría & No & Sí & Sí \\
\hline
\end{tabular}

En referencia a las páginas de tercer nivel, o apartados, los datos obtenidos indican que la imagen es el contenido predominante sólo en una de las 3 páginas. 
Se observa una notable desigualdad en cuanto al número de fotos que se publican en este nivel, así como en la variedad de tamaños de las mismas. En aquellas páginas donde se publica más de una foto, se compone siempre con una de ellas a tamaño mayor que el resto, y asimismo es apreciable que la utilización de fotografías de tipo "miniatura" es bastante escasa. No se entremezclan fotografías con otros elementos visuales ni con publicidad en ninguna de las páginas de este nivel jerárquico, y todas ellas se asocian claramente con los textos a los que se refieren. La utilización de pies de foto en este nivel únicamente se da uno de los tres casos, igual proporción que el empleo de texto sobrescrito en la imagen. Sí se cita la autoría de las imágenes en 2 de las 3 páginas.

Tabla 8. Rasgos intrínsecos a la fotografía en apartados

\begin{tabular}{|l|c|c|c|}
\hline \multicolumn{4}{|c|}{ Rasgos intrínsecos a la fotografía } \\
\hline Indicadores & P3 & JPN & Ciência 2.0 \\
\hline Valor noticioso & $\begin{array}{c}100 \% \text { decorativo- } \\
\text { ilustrativo }\end{array}$ & $\begin{array}{c}100 \% \text { decorativo- } \\
\text { ilustrativo }\end{array}$ & $\begin{array}{c}100 \text { \% decorativo- } \\
\text { ilustrativo }\end{array}$ \\
\hline Encuadre predominante & $\begin{array}{c}81,7 \% \text { corto-medio } \\
18,1 \% \text { general }\end{array}$ & $\begin{array}{c}66,6 \% \text { corto-medio } \\
33,4 \% \text { general }(*)\end{array}$ & $\begin{array}{c}80 \text { corto-medio } \\
20 \% \text { general }\end{array}$ \\
\hline Retrato o posado & Sí & Sí & Sí \\
\hline $\begin{array}{l}\text { Fotos genéricas o de } \\
\text { avatar }\end{array}$ & $(0,9 \%)$ & No & No \\
\hline Fotomontaje & No & No & No \\
\hline $\begin{array}{l}(*) \text { Estos valores coinciden con los de las páginas de las secciones, ya que siempre se reproduce en } \\
\text { los apartados la misma foto de la sección que le da acceso. }\end{array}$
\end{tabular}

Según los datos expuestos en la Tabla 8:

Al igual que en las páginas de jerarquía superior, en los apartados el valor noticioso de las fotografías se reduce en todos los casos al mínimo, limitándose a cumplir una función ilustrativo-decorativa. Existe un claro predominio de los encuadres cortos, y se utilizan fotos de posado o retrato en todos los casos. El empleo de fotos genéricas o de avatar se da sólo en una de las páginas, y corresponde a un porcentaje mínimo de imágenes. No publican fotomontajes las páginas de este nivel.

Tabla 9. Características interactivas en fotografías en apartados

\begin{tabular}{|l|c|c|c|}
\hline \multicolumn{4}{|c|}{ Características interactivas } \\
\hline Indicadores & P3 & JPN & Ciência 2.0 \\
\hline Fotografías con vínculo & $100 \%\left(^{*}\right)$ & $0 \%$ & $0 \%$ \\
\hline Se indica que la foto lleva vínculo & No & - & - \\
\hline Efectos on-mouse & Sí & - & - \\
\hline Tipo de destino & Interno & - & - \\
\hline $\begin{array}{l}\text { Visualización en destino de la misma } \\
\text { fotografía }\end{array}$ & Variable & - & - \\
\hline $\begin{array}{l}(*) \text { Debe tenerse en cuenta que el portal P3 es el único de los analizados cuya arquitectura de } \\
\text { contenidos posee más de tres niveles de profundidad. }\end{array}$ \\
\hline
\end{tabular}


En relación a las características de interactividad en páginas de este nivel jerárquico, sólo en un caso se publican fotografías que incluyen vínculos. Esto se corresponde con el único de los portales evaluados (P3) que posee más de 3 niveles de profundidad estructural. Al igual que en otros niveles, no hay indicativos estáticos de la existencia de vínculos en las imágenes, y se requiere que el usuario sitúe el ratón sobre las imágenes con vínculo, para que éstas muestren efectos visuales dinámicos (tipo roll-over). Otro aspecto también reiterado es que la totalidad de los vínculos en fotografías tienen como destino documentos internos, es decir, situados dentro del mismo sitio web. En este caso, el documento o elemento de destino no siempre muestra esa misma fotografía.

\subsubsection{CONTRASTE DE RESULTADOS ENTRE NIVELES JERÁRQUICOS}

A partir de los datos expuestos en el epígrafe anterior, se aprecia la existencia de algunas diferencias en cuatro al tratamiento de las características consideradas, según el nivel jerárquico al que pertenecen las páginas. Las divergencias más significativas en dicho sentido son:

Factores de contexto de página:

- Se observa un mayor predominio de la imagen en las páginas de nivel jerárquico más alto, mientras que las de tercer nivel tienen un carácter más textual, lo cual es lógico teniendo en cuenta que por lo general en ellas se realiza la narración detallada y monográfica de un hecho o asunto específico.

- El número de fotografías y de tamaños de las mismas desciende conforme la página pertenece a un nivel más profundo. Asimismo, el empleo de fotos "miniatura" se reduce en las páginas de nivel más profundo, lo que se relaciona con el hecho de que en las mismas se maquetan las imágenes a mayor tamaño.

- Mientras que en las páginas principales siempre se compone con una foto de tamaño mayor que el resto, este recurso de jerarquización es menos utilizado en apartados y secciones.

- La tendencia a entremezclar fotografías con otros tipos de imágenes y con publicidad es mayor en las páginas principales y secciones que en los apartados.

- No hay grandes diferencias dependientes del nivel de la página en cuanto a la asociación correcta de la imagen y el texto que ilustra.

- Los pies de foto y las citas de autoría únicamente se emplean en las páginas de jerarquía más profunda, que son aquellas donde el tamaño de las fotos es mayor. Hay mayor tendencia a utilizar el texto sobrescrito en las fotografías de las páginas principales que en el resto. 
Rasgos intrínsecos a la fotografía:

- El valor noticioso dominante no guarda relación con el nivel jerárquico de las páginas: en todos los casos es decorativo-ilustrativo.

- En las páginas pertenecientes al segundo y tercer nivel jerárquico (apartados y secciones) se incluyen más fotografías de encuadre general que en las principales.

- No hay diferencias relevantes en cuanto al empleo de posados o retratos y de fotografías genéricas o de avatar por niveles jerárquicos.

- Únicamente se observa la publicación de fotomontajes en páginas de primer y segundo nivel jerárquico.

\section{Características interactivas:}

- La utilización de fotografías con vínculos disminuye ligeramente conforme se trata de páginas situadas en el nivel jerárquico más profundo, debido a que, en su mayor parte, los vínculos ofrecen acceso a páginas de nivel inferior, y en este caso no hay otros por debajo.

- No se aprecia correlación clara entre el nivel jerárquico al que pertenece la página y aspectos como el empleo de indicativos visuales en las fotos con vínculo, el destino de los vínculos (interno en todos los casos) y el hecho de que se visualice la misma imagen de origen en la que se sitúa el anclaje de origen del vínculo.

\section{CONCLUSIONES}

A partir de los resultados expuestos, cabe realizar una interpretación de los mismos en relación al marco teórico y los objetivos de trabajo. Para ello se tendrán en cuenta los valores de idoneidad de los indicadores evaluados y las consideraciones previamente realizadas al respecto.

1. Los dos portales periodísticos analizados en este trabajo con orientación más próxima al ámbito profesional (P3 y Ciência 2.0) siguen claramente la tendencia de enfatizar los elementos visuales frente a los textuales imperantes en la mayor parte de los rediseños recientes de la prensa digital internacional. Las fotografías gozan de un espacio y relevancia destacados, aunque por el momento también en estos medios de ámbito universitario es fundamentalmente un auge más cuantitativo que cualitativo.

2. En relación a las carencias constatadas por investigaciones precedentes sobre el tratamiento de la fotografía en grandes medios digitales de prensa online, se aprecia que en los portales de ámbito universitario se hace un uso menos masificado de la fotografía, especialmente en las páginas principales, lo que redunda en beneficio de la claridad. No obstante, persisten los aspectos 
negativos sustanciales, como el exceso de fotografías muy pequeñas y, especialmente, la casi irrelevante aportación noticiosa de las mismas.

3. El procedimiento de análisis y el instrumento diseñado al efecto ha permitido examinar diferentes dimensiones del tratamiento fotoperiodístico en medios de prensa digitales, algunos de las cuales han sido escasamente contempladas con anterioridad, sobre las que quizás quepa una mayor profundización a través de futuros estudios.

4. Los aspectos más positivos observados con carácter general son los siguientes:

a) Desde el punto de vista cuantitativo, en los portales P3 y Ciência 2.0 la imagen en general y a la fotografía en particular posee un protagonismo destacado, dentro de un contexto gráfico general limpio, dotado de blancos generosos. En ambos casos se trata de sitios web muy visuales, y en dicho sentido plenamente equiparables con la tendencia imperante en la actualidad en la prensa digital profesional.

b) Aunque el número de imágenes publicadas es alto, no se produce en ningún caso la masificación que tan frecuente es en las páginas principales los grandes periódicos digitales. Esta diferencia quizás pueda justificarse por la gran cantidad y variedad de contenido que albergan los medios profesionales, en contraste con el relativamente escaso los portales de ámbito universitario aquí analizados. Ello beneficia la claridad visual de éstos últimos respecto a los anteriores.

c) El empleo de tamaños diferentes para las fotografías en una misma página contribuye a su correcta jerarquización y otorga mayor atractivo a la composición, al destacar de manera más evidente unas respeto de otras. La maquetación con una fotografía más grande que las demás se utiliza con frecuencia en JPN y Ciência 2.0, y se siempre adopta como pauta en P3, lo que refuerza aún más el efecto de jerarquización.

d) Las fotografías más grandes presentan un tamaño de visualización que permite apreciar aceptablemente los detalles. Esta tendencia también se aprecia en los nuevos rediseños de los grandes diarios digitales. En dicha práctica destaca positivamente el portal Ciência 2.0 respecto a los P3 y JPN.

e) La asociación entre las imágenes y los textos a los que aluden es inequívoca en las páginas analizadas, y en todos los niveles estructurales de los tres portales.

f) En los tres portales analizados se aprecia un alto grado de coherencia interna, lo que implica que el tratamiento de la fotografía, en cuanto a maquetación y estilismo, es semejante en todas las páginas del mismo nivel 
jerárquico. Esto refuerza la homogeneidad del sitio y facilita la claridad y la intuitividad de cara al usuario.

g) El uso de la fotografía como elemento interactivo es mayoritario, sin llegar a ser general. Respecto su funcionalidad, destaca positivamente la coherencia en cuanto al tipo de destinos de los vínculos, que siempre son internos.

h) En el portal JPN la fotografía sirve como hilo conductor visual de la navegación por páginas de diferentes niveles, ya que siempre se presenta la misma foto para la misma noticia. P3 y Ciência 2.0 también utilizan esta praxis, aunque no de manera sistemática.

5. Los aspectos que presentan un tratamiento más débil son los siguientes:

a) Aunque el tamaño de las fotos más grandes es aceptable, se aprecia un exceso de fotografías de tipo "miniatura", que por su pequeñez resultan irrelevantes. Esto es especialmente acusado en el portal JPN y algo menos en P3, pero no así en Ciência 2.0.

b) La mezcla de fotografías con otro tipo de imágenes (dibujos, collages, e incluso publicidad) sin separación clara es habitual en las páginas de los dos niveles jerárquicos superiores de P3. En Ciência 2.0 se produce un recurso excesivo a los menús de navegación visuales de tipo "carrusel” ubicados en la parte superior de la página principal y compuestos por fotografías, que simplemente son un elemento decorativo de navegación.

c) El empleo de pies de foto es muy escaso, si bien se compensa en P3 y JPN con el texto sobrescrito en las imágenes de mayor tamaño, lo cual es una práctica que cobra vigencia gradualmente. Ciência 2.0 es el medio con un tratamiento más deficiente en este aspecto.

d) Se constata un nivel muy bajo de identificación de la autoría, y ésta sólo se da en fotografías pertenecientes a páginas de nivel jerárquico más profundo.

e) La inmensa mayoría de las fotografías publicadas en los portales poseen una función simplemente decorativa o ilustrativa, es decir, carente de valor informativo real. Se trata de una carencia de importancia capital, porque afecta a la esencia periodística de la imagen, y constituye también la principal insuficiencia ya acreditada en las investigaciones sobre los grandes medios de prensa digital anteriormente aludidas.

f) El uso excesivo a fotografías de encuadres cortos y medios, así como de retratos y posados, supone un factor de monotonía en el tratamiento general de la imagen. Una mayor cantidad de fotografías en plano general contribuiría mejorar este indicador, aunque ello está ligado con el tamaño al que se publiquen las fotos, ya que cuando mayor es éste también lo es la facilidad de visualización de detalles en encuadres abiertos. Este mismo fallo se ha venido observando asimismo en las grandes cabeceras de prensa digital. 
g) No hay indicaciones estáticas o textuales de que las fotografías llevan vínculo asociado, salvo si el usuario sitúa el ratón sobre la propia imagen; cuando esto se produce, todas las fotografías de P3 llevan incorporado un efecto dinámico on-mouse de tipo roll-over, del que también se dispone en Ciência 2.0, pero sólo en aquellas que se publican en la página principal. JPN no hace uso de estos efectos.

6. El diseño y aplicación de modelos de análisis sistemáticos, que contemplen e integren todas las características posibles del tratamiento de fotografía en la prensa digital, puede resultar de utilidad para la investigación en el entorno académico, así como en la mejora de los estándares de calidad del propio producto periodístico.

7. La naturaleza dinámica y cambiante de los medios de comunicación en soporte digital hace aconsejable la realización periódica de estudios que den cuenta de su evolución. La diversidad de enfoques y productos abre numerosas vías de ampliación para futuros trabajos: en mayor número de portales, en medios generalistas y especializados, en medios de prensa comerciales y no comerciales, además de otros de carácter comparativo.

\section{REFERECIAS BIBLIOGRÁFICAS}

ALONSO ERAUSQUIN, Manuel. (1995) Fotoperiodismo: Formas y códigos. Madrid: Síntesis.

BRUDER, Katherine (2007) "The Effects of News Photographs on a Readers's Retention”. COM 350.

www.katebruder.com/Writing_\&_Design_files/Photographs\%20and\%20Informati on\%20Retention.pdf [Consulta: 11/08/2015]

CAMINOS, José $\mathrm{M}^{\mathrm{a}}$; MARTÍN, Flora; ARMENTIA, José Ignacio (2008). "Novedades en el diseño de la prensa digital española (2000-2008)". Palabra Clave, 11, 2, pp. 253-269

HASSAN MONTERO, Yusuf. y MARTÍN FERNÁNDEZ, F.J. (2003). "Guía de evaluación heurística para sitios web”. No sólo usabilidad. com. http://www.nosolousabilidad.com/articulos/heuristica.htm [Consulta: 22/08/2015].

HORTON, Sarah (2006). Universal Usability. A universal design approach to web usability. Berkeley CA, New Riders Press. Versión en línea. http://www.universalusability.com/index.html

[Consulta: 19/08/2015]

IGARTUA, Juan José (2007). Métodos cuantitativos de investigación en comunicación. Barcelona: Bosch.

ISO 9241-11 (1998). Ergonomic requirements for office work with visual display terminals (VDT)s. Part 11 Guidance on usability. 
KRUG, Steve (2006). No me hagas pensar. Madrid: Pearson.

KÜPPER, Norbert (2015). "European Newspaper Award. $16^{\text {th }}$ Competition". http://issuu.com/newspaperdesign/docs/ena_16_00_introduction_chief_winn [Consulta: 26/08/2015]

LÓPEZ DEL RAMO, Joaquín (2010). "El tratamiento fotoperiodístico en las portadas de los diarios digitales. Propuesta y aplicación de un modelo de análisis”. Doxa Comunicación n ${ }^{\circ} 11$, pp. 77-99

LÓPEZ DEL RAMO, Joaquín (2014). "Modelo de análisis de contenido de la fotografía periodística desde el plano documental e informativo”. Registro de la Propiedad Intelectual como obra científica. Número M-001449/2014.

MARSH, Emily E;WHITE, Marilyn Domas (2003). “A taxonomy of relationships between images and text”. Journal of Documentation, 59, 6; ProQuest Business Collection, pp. 647-672

MARZAL FELICI, Javier (2004). "Metodología de análisis de la fotografía”. Web www.analisisfotografia.uji.es/root2/METODOLOGIA\%20ANALISIS\%20FOTO \%2023-11-2007.pdf [Consulta: 02/09/2015].

MASIP, Pere; MICÓ, Josep Lluis; MESO, Koldo (2012). "Periodismo multimedia en España. Análisis de los contenidos multimedia en la prensa digital”, Actas III Congreso Asociación Española de Investigación en Tarragona 2012. Disponible en: http://www.ae-ic.org/tarragona2012/contents/comunicacions_cd /ok/100.pdf [Consulta: 08/08/2015].

NIELSEN, Jacob; LORANGER, Loa (2006). Usabilidad. Prioridad en el diseño web. Madrid: Anaya Multimedia.

RODRIGUEZ MERCHÁN, Eduardo (1993). La realidad fragmentada. Madrid: Universidad Complutense.

SÁNCHEZ VIGIL, Juan Miguel (2011). "Patrimonio fotográfico en las instituciones públicas españolas: modelos de uso y reproducción” en El Profesional de la información, julio-agosto, vol. 20, nº 4, pp.371-377.

SÁNCHEZ VIGIL, Juan Miguel; MARCOS, Juan Carlos; OLIVERA, María (2011). "La fotografía en los diarios digitales: aplicaciones, usos y diseños”, en RÍOS ORTEGA, J. (Coord) Memoria, $7^{\circ}$ Seminario Hispano-Mexicano de investigación en Bibliotecología y Documentación. Universidad Nacional Autónoma de México.

- (2014). "Tesis doctorales sobre fotografía en la universidad española. Análisis de

la producción y dirección (1976-2012)”, en Revista Española de Documentación Científica, vol. 37, $\mathrm{n}^{\circ} 1$.

SOUSA, Jorge Pedro (2004) Fotojornalismo. Introdução à história, às técnicas e à linguagem da fotografia na imprensa. Florianópolis-SC: Letras Contemporâneas.

STROUD, Natalie; CURRY, Alex; CARDONA, Arielle; PEACOCK, Cynthia (2015). "Homepage Layout". Engaging News Project. 
http://engagingnewsproject.org/enp_prod/wp-content/uploads/2015/07/OnlineNews-Presentation-White-Paper1.pdf [Consulta: 25/08/2015]

VAN DUSSELDORP, Monique (2007). "Newspapers: Not Visual Enough for the Future?” Pointer.org. http://www.poynter.org/news/80421/newspapers-notvisual-enough-for-the-future/_[Consulta: 10/08/2015]

VILCHES, Lorenzo. (1993) Teoría de la imagen periodística. Barcelona: Paidós. 